\title{
Effectiveness of non-pharmacological interventions to manage anxiety in adolescents in the perioperative period: A systematic review and meta-analysis
}

Follow this and additional works at: https://www.journal.acorn.org.au/jpn

(c) (i)

This work is licensed under a Creative Commons Attribution 4.0 License.

\section{Recommended Citation}

Pestana-Santos, Marcia; Pereira, Maria Joao; Pestana-Santos, Adriana; Santos, Eduardo; Goncalves, Andreia; Cardoso, Daniela; Lomba, Lurdes; and Santos, Margarida Reis (2021) "Effectiveness of nonpharmacological interventions to manage anxiety in adolescents in the perioperative period: A systematic review and meta-analysis," Journal of Perioperative Nursing: Vol. 34 : Iss. 3 , Article 3.

Available at: https://doi.org/10.26550/2209-1092.1130

https://www.journal.acorn.org.au/jpn/vol34/iss3/3

This Article is brought to you for free and open access by Journal of Perioperative Nursing. It has been accepted for inclusion in Journal of Perioperative Nursing by an authorized editor of Journal of Perioperative Nursing. 


\section{Effectiveness of non-pharmacological interventions to manage anxiety in}

adolescents in the perioperative period: A systematic review and meta-analysis

\section{Cover Page Footnote}

Funding Statement This research received no specific grant from any funding agency in the public, commercial, or not-for-profit sectors. Conflicts of interest statement The authors declare no conflict of interest. 


\section{Authors}

Marcia Pestana-Santos

PhDc, RN

Instituto Ciências Biomédicas de Abel

Salazar

Maria João Pereira

MSc, RN

Escola Superior de Enfermagem do Porto

Adriana Pestana-Santos

MSc, MD

Instituto Português de Oncologia FG

Coimbra

Eduardo Santos

PhD, RN

Departamento Reumatologia. CHUC

Andreia Goncalves

PhDc, RN

Instituto Ciências Biomédicas de Abel

Salazar

Daniela Cardoso

PhD, RN

Portugal Centre for Evidence-Based

Practice: A Joanna Briggs Institute Centre

of Excellence, Coimbra, Portugal. Health

Sciences Research Unit: Nursing (UICISA:

E), Nursing School of Coimbra (ESEnfC),

Coimbra, Portugal

Lurdes Lomba

PhD, RN

Portugal Centre for Evidence-Based

Practice: A Joanna Briggs Institute Centre of Excellence, Coimbra, Portugal. Health

Sciences Research Unit: Nursing (UICISA:

E), Nursing School of Coimbra (ESEnfC),

Coimbra, Portugal

Margarida Reis Santos

PhD, RN

Instituto Ciências Biomédicas de Abel Salazar; Escola Superior de Enfermagem do Porto; CINTESIS

\section{Corresponding author}

Marcia Pestana-Santos

PhDc, RN

Instituto Ciências Biomédicas de Abel

Salazar

marcianpsantos@gmail.com

\section{Effectiveness of non-pharmacological interventions to manage anxiety in adolescents in the perioperative period: A systematic review and meta-analysis}

\author{
Abstract \\ Aims \\ To evaluate the effectiveness of non-pharmacological interventions to manage \\ anxiety in adolescents in the perioperative period.

\section{Design} \\ Systematic review of effectiveness and meta-analysis.

\section{Data sources} \\ MEDLINE, CINAHL, PsycInfo, Cochrane Central Register of Controlled Trials, \\ SciELO, sources of unpublished studies and grey literature, including Open \\ Grey and RCAAP - Portugal, were systematically searched without time limits \\ (up to December 2020).
}

\section{Review methods}

This review followed the Joanna Briggs Institute (JBI) methodology for systematic reviews of evidence effectiveness. The selection process, critical analysis and extraction of data were performed by two independent reviewers. Studies were critically appraised using JBI Critical Appraisal Checklist for Randomised Controlled Trials. Data was synthesised through meta-analysis (using a fixed-effect model in the RevMan 5.2.8) and narrative synthesis.

\section{Results}

This analysis included five studies with a total of 420 adolescents. The effectiveness of non-pharmacological interventions, including cognitivebehavioural techniques, hypnosis, guided imagery and relaxation, were examined in the perioperative context. A meta-analysis ( $n=136$ adolescents) of three studies suggests no differences in adolescents' anxiety when nonpharmacological interventions are applied compared to standard care ( $S M D-0.14,95 \% \mathrm{Cl}-0.48$ to $0.20, p=0.42$ ). Individually, all the studies showed that non-pharmacological interventions were beneficial on the reduction of the adolescents' anxiety, although no statistical significance was found.

\section{Conclusion}

Despite insufficient evidence on the effectiveness of non-pharmacological interventions, they should be considered as a resource in the management of adolescent anxiety in the perioperative period.

Key words: adolescent, anxiety, perioperative care, nursing, systematic review, non-pharmacological, guided imagery, education 


\section{Introduction}

Anxiety is a common symptom in adolescents undergoing surgery? Up to 65 per cent of adolescents that undergo surgery experience considerable anxiety symptoms before the procedure 1 . The highest scores are generally reported just before the start of anaesthesia, in the induction room, where about 80 per cent of individuals present very high levels of anxiety?. It is estimated that about five million adolescents in the United States of America and 65000 in Canada experience a surgical procedure each year ${ }^{2,3}$. In Portugal, of the 970200 surgeries performed in 2018, 17482 were at paediatric age - up to 14 years old 4 . Although efforts were made to find data from a global number or even from other countries, it was not possible to find discriminated surgical statistics for the adolescent or paediatric groups.

The World Health Organization (WHO) defines adolescence as the phase between childhood and adulthood ranging from 10 to 19 years old ${ }^{5}$. Given the developmental characteristics, adolescence can be divided into three stages: early adolescence (10-14 years), medium adolescence (15-16 years) and late adolescence (17-19 years) 6 . This specific population experiences rapid physical, cognitive and psychosocial development ${ }^{5}$. However, physical growth precedes cognitive maturation ${ }^{7}$ and both emotional and judgmental maturation are important cofactors for perioperative care ${ }^{8}$.

Non-pharmacological interventions (NPIs) implemented in the preoperative period help to reduce anticipatory anxiety and preoperative anxiety by offering a peaceful and pleasant state 9 . The NPIs can also complement pharmacological interventions offering a feeling of well-being ${ }^{9}$.
The behaviour of the paediatric population in a perioperative situation has been widely studied, and many reviews have been conducted on the topic c $^{10-13}$. Despite adolescents being included in these studies, the specific subject of NPIs how these could be used and which effects to expect on adolescent's perioperative anxiety - was not reported. This is particularly relevant if we attend to developmental characteristics and want to know which NPI could be better suited for the adolescent population.

\section{Background}

Adolescents' anxiety in the perioperative period frequently results from fear of the unknown, fear of the inability to wake up, fear of death after anaesthesia, loss of control and pain ${ }^{14,15}$. But anxiety can last past the surgical experience. Some adolescents revealed trouble sleeping, nightmares and waking up with an intense sense of fear and anxiety, that lasted longer than the recovery period ${ }^{16}$. Even for those individuals who have been provided with information about the surgical procedure, the perioperative experience may still be distressing and overwhelming ${ }^{10}$. In general, the child/adolescent anticipates the surgical experience according to their maturity, previous information and involvement in the treatment process $^{17}$.

Anxiety can be defined as an emotional state that involves feelings of apprehension, tension, nervousness and worry accompanied by physiological or motor arousal ${ }^{18}$. It is a normal reaction to any threat, and it can be protective under some circumstances. Anxiety can also be associated with the anticipation of a future concern and is more correlated with muscle tension and avoidance behaviour ${ }^{19,20}$. A fearful temperament, somatisation tendencies, trait anxiety and depression are significant predictors for pre-operative anxiety in the adolescent ${ }^{1}$. The triggering factors for anxiety in the perioperative period are related to how the patient fears the unknown; perceives physical injuries, pain and loss of control, and the uncertainty of what is expected in the immediate experience ${ }^{21}$. Perioperative anxiety can consequently require a longer time for induction of anesthesia and post-operative recovery, increase the risk of post-operative delirium and increase pain scores and the consumption of analgesia ${ }^{22}$.

In the last decade, a substantial investment has been made in studies focusing on the neurocognitive development processes of adolescents, to clarify why they react and behave differently from not only children but also from adults ${ }^{23}$. A decade ago, Fortier and colleagues highlighted the need to develop primary studies in the perioperative context, involving adolescents only in their samples'. Some studies conducted in the perioperative period demonstrated contradictory results for the relationship between anxiety and age, gender and previous medical experiences ${ }^{24-26}$. Nevertheless, the higher the scores of anxiety, the greater are adolescents' negative emotions and difficulties with pain management and dealing with health care professionals ${ }^{27}$.

The State-Trait Anxiety Inventory form $Y$ (STAI-Y) is an instrument for assessing state of anxiety (20-items) and trait of anxiety (20-items), with each one scoring between 20 and $80^{18}$. The STAI for children (STAIC) has scores ranging from 20 to 60 , with higher scores indicating greater anxiety ${ }^{18}$. Both instruments are considered 'gold standard' in the evaluation of adolescents' anxiety in the perioperative period ${ }^{18}$. The Visual Analogue Scale for Anxiety (VAS-A) 
and the Numeric Rating Scale (NRS) are also often used and easy to apply. The scores range from 0 to 10 and higher scores indicate greater anxiety.

The interventions used to prevent anxiety in the preoperative period include both non-pharmacological and pharmacological strategies ${ }^{28,29}$. The former allow changes to the meaning attributed to the anxiety-causing agent. That is, NPIs achieve cognitive restructuring which is oriented to the cognitions, expectations, assessments and constructions that complement the experience of anxiety ${ }^{30}$. Furthermore, NPIs have no side effects, no need for a prescription, are recommended as a resource in the control of adolescent anxiety and fear related to surgical procedures, and the adolescent can use them as tools to manage other anxiety situations throughout life ${ }^{30}$.

The NPIs are differentiated into five categories: psychological, physical, nutritional, digital and elemental health interventions ${ }^{31}$. Psychological interventions include relaxation therapies, health education programs, psychotherapies and body-mind programs $^{31,32}$. The use of these NPIs is safe and has no adverse reactions ${ }^{32}$.

A preliminary search throughout MEDLINE, PROSPERO, Joanna Briggs Institute (JBI) Database of Systematic Reviews and Implementation Reports and the Cochrane Database of Systematic Reviews was conducted and found some systematic reviews

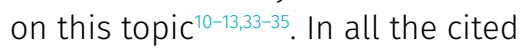
studies, the authors do not present results for the adolescent population. Additionally, a previous scoping review identified which NPIs are used with the adolescent population in the perioperative period but the effects, alone or grouped, have not yet been evaluated ${ }^{36}$. Therefore, there is a need to systematise the findings, focusing on the NPIs and the management of anxiety in adolescents in the perioperative period, and produce the best evidence for the health care professionals who work with this population in this context.

\section{The review}

\section{Aim}

This review aimed to evaluate the effectiveness of non-pharmacological interventions to manage anxiety in adolescents in the perioperative period.

The following review question was addressed in this study: What is the effectiveness of non-pharmacological interventions to manage anxiety in adolescents in the perioperative period?

\section{Design}

This systematic review was conducted according to the JBI methodology for systematic reviews of effectiveness ${ }^{37}$ and this report was organised using the Preferred Reporting Items for Systematic Reviews and Metaanalyses (PRISMA 2020) statement. The review protocol was registered in PROSPERO (CRD42020184386) and previously published ${ }^{38}$ to increase transparency and reduce the risk of bias.

\section{Search methods}

The search followed a three-step strategy to identify both published and unpublished studies that met the inclusion criteria (Table 1). Initially a limited search of MEDLINE (Pubmed) and CINAHL (EBSCO) was undertaken and followed by an analysis of the relevant text words included in the title and abstract and the index terms of the selected articles. All the identified keywords and index terms were adapted for each database and a second search was undertaken in December 2020.
The searched databases included MEDLINE (PubMed), CINAHL (EBSCO), PsycInfo (EBSCO), Cochrane Central Register of Controlled Trials (EBSCO) and SciELO. Sources of unpublished studies and grey literature searched included Open Grey and RCAAP Portugal Open Access Scientific Repository. The full search strategies are provided in Supplement 1. Finally, all references of the studies selected for critical appraisal were screened to find additional studies. Studies published in English, Spanish and Portuguese were considered for inclusion. No date or geographical limits were applied to this review.

\section{Search outcomes}

A total of 985 potentially relevant studies were identified from the database searches. All identified citations were collated and uploaded into the citation manager EndNote X8 (Clarivate Analytics, PA, USA) and duplicates were removed. After the full text of the selected studies was examined, the titles and abstracts of the remaining studies were screened to check whether they met the inclusion criteria. These steps were undertaken by two independent reviewers (MPS, MJP) and any disagreements between both were discussed jointly or with a third reviewer (APS).

\section{Quality appraisal}

Eligible studies were critically appraised by two independent reviewers using the JBI Critical Appraisal Checklist for Randomised Controlled Trials ${ }^{37}$. All items have three potential responses 'yes', 'unclear' and 'no', with 'yes' scoring 1, and the others 0 . The quality of the RCT studies were classified into good (score 11-13), moderate (score 7-10) and poor (score <6). Once again, any disagreements between reviewers were discussed jointly or with a third reviewer (APS). Considering 
Table 1: Inclusion criteria based on population, intervention, control, outcomes and study (PICOS) format

\begin{tabular}{|l|l|}
\hline Review question & Inclusion criteria \\
\hline Population & $\begin{array}{l}\text { Adolescents (10-19 years) in the perioperative } \\
\text { Intervention }\end{array}$ \\
\hline Comparator & $\begin{array}{l}\text { NPIs such as education, massage, hypnosis, guided } \\
\text { imagery, music therapy, music or virtual reality. } \\
\text { There were no limitations in frequency, intensity or } \\
\text { who delivers the intervention. }\end{array}$ \\
\hline Outcome & Usual/standard care \\
\hline Studies & $\begin{array}{l}\text { Anxiety (STAI-Y or STAIC or VAS-A or NRS) } \\
\text { Experimental and quasi-experimental study } \\
\text { designs including randomised controlled trials } \\
\text { (RCTs), non-randomised controlled trials, before } \\
\text { and after studies, and interrupted time-series } \\
\text { studies. Analytical observational studies including } \\
\text { prospective and retrospective cohort studies, case } \\
\text { control studies and analytical cross-sectional } \\
\text { studies. }\end{array}$ \\
\hline
\end{tabular}

there were few studies concerning the use of NPIs to manage anxiety in adolescents in the perioperative period, researchers decided to include all the selected studies and discuss their methodological weaknesses ${ }^{38}$.

\section{Data abstraction}

Data from the included studies was extracted by the same two independent reviewers (MPS, MJP) using the standardised $\mathrm{JBI}$ data extraction tool (JBI SUMARI) ${ }^{37}$. Data extracted included: study design, participant's details, setting and location, intervention (frequency, duration, dose), comparator, outcome measures, measurements points and outcomes of significance to the review objective.

\section{Synthesis} meta-analysis using Review Manager 5.2.8. (Copenhagen: The Nordic Cochrane Centre, The Cochrane Collaboration, 2011). Effect sizes expressed as standardised final post-intervention mean differences (for continuous data) and their 95 per cent confidence intervals were calculated for analysis. Heterogeneity was assessed statistically using the standard $X^{2}$ and $P$ tests. Statistical analyses were performed using fixedeffect models due to the absence of heterogeneity $\left(R^{2}=0 \%\right)^{39}$. Subgroup analyses were not conducted due to insufficient data. As there were fewer than ten studies included in the meta-analysis, it was not possible to assess publication bias and generate the funnel plot. Where statistical pooling was not possible, the findings are presented and synthesised in narrative format, without meta-analysis.
Studies were pooled with statistical

\section{Results}

A total of 58 papers were retrieved for full-text review. Of these, 53 articles were excluded and reasons are noted in Supplement 2. Five studies were critically assessed and included in this review. The study identification is described in detail in Figure 1.

\section{Methodological quality}

Although different study designs were considered for inclusion, only RCTs met the criteria and all of them were of moderate quality ${ }^{40-44}$.

In the standardised critical appraisal instrument for RCTs, seven out of 13 questions about the studies were rated as 'yes' (Table 2 ). None of the RCTs provided sufficient information about whether those delivering the treatment were blinded to treatment assignment. With the exception of one ${ }^{42}$, the studies used clear randomisation for assignment to the treatment or control group and allocation to treatment group was concealed. Another study ${ }^{44}$ clearly describes that the participants were blind to the treatment assignment, and only two studies ${ }^{42,43}$ outline in a clear way that those delivering the treatment were blind to treatment assignment. At last, only one study ${ }^{41}$ presents a complete follow-up.

\section{Characteristics of included studies}

All the studies included in this review were published between 2003 and 2019 and are written in English. Specific information and characteristics of these studies are summarised in Table 3. 

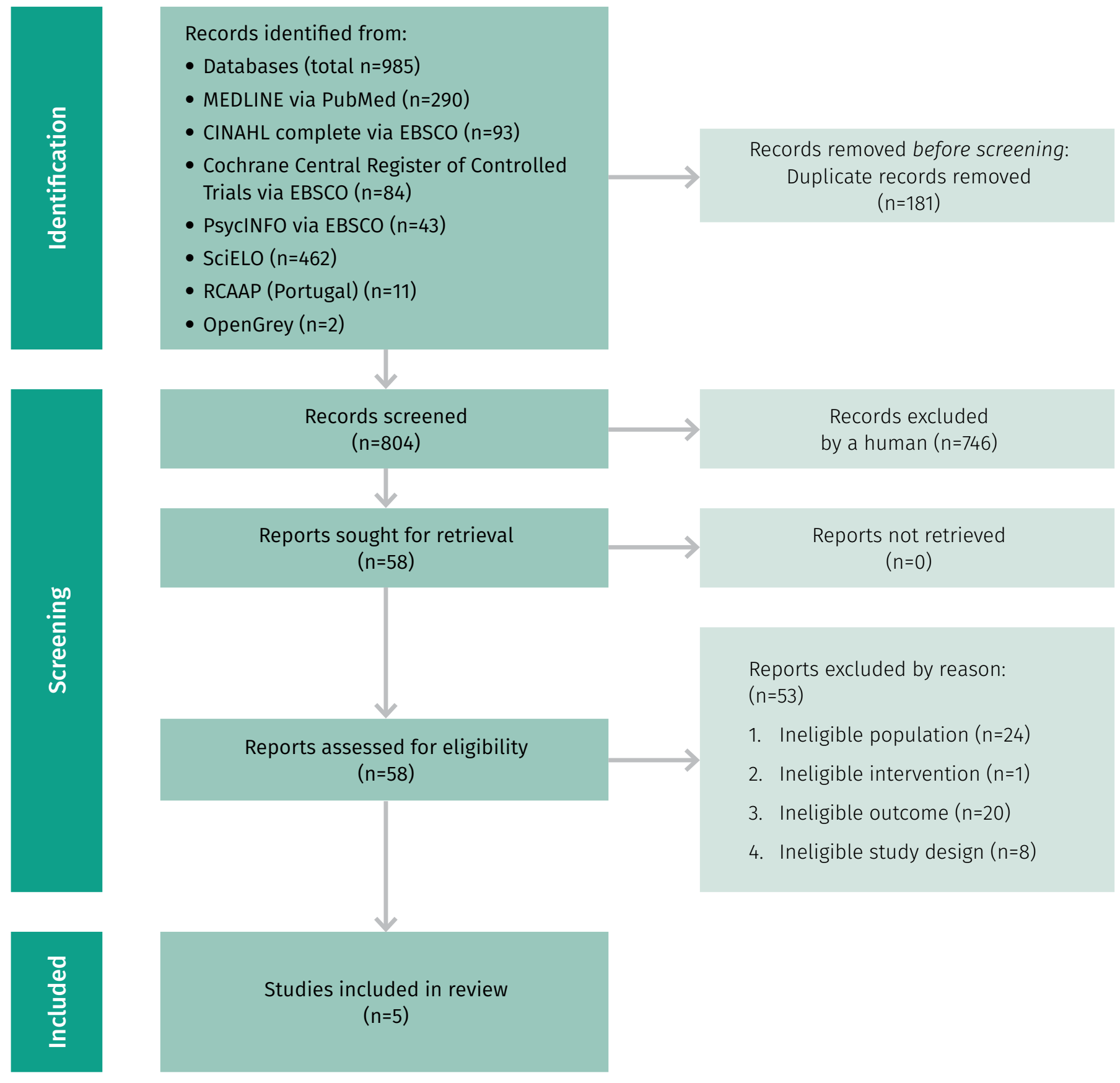

Records identified from:

Databases (total $n=985$ )

- MEDLINE via PubMed $(n=290)$

- CINAHL complete via EBSCO ( $n=93)$

- Cochrane Central Register of Controlled Trials via EBSCO $(n=84)$

- PsyciNFO via EBSCO $(n=43)$

- SciELO ( $n=462)$

RCAAP (Portus

OpenGrey $(n=2)$

Records excluded by a human $(n=746)$

Figure 1: PRISMA 2020 flow diagram including searches of databases

From: Page MJ, McKenzie JE, Bossuyt PM, Boutron I, Hoffmann TC, Mulrow CD, et al. The PRISMA 2020 statement: an updated guideline for reporting systematic reviews. BMJ 2021;372:n71. doi: 10.1136/bmj.n71. 


\section{Settings}

Two studies were conducted in the United States of America (USA) ${ }^{40,42}$, one in France ${ }^{43}$, one in Canada ${ }^{41}$ and one in Poland ${ }^{44}$. All the studies were developed in a hospital context though in different clinical settings: orthopaedics ${ }^{40-42}$, thoracic paediatric surgery ${ }^{44}$ and the operating room just before anaesthesia induction ${ }^{43}$.

\section{Sample size}

The number of participants varied from $40^{41}$ to $118^{43}$ per study. At pre-intervention the included studies had a total sample of 437 participants. However, at postintervention the total sample had 420 participants. Of these, 279 were females and 141 were males.

\section{Participants}

The participants' ages ranged from 9 to 19 years old. Only one study ${ }^{44}$ included participants aged nine years. Authors of this study were contacted to ascertain exactly how many nine-year-olds were included in the sample. As there were only two, after a thorough discussion, the

\section{Table 2: Quality appraisal of eligible studies}

\begin{tabular}{|c|c|c|c|c|c|c|}
\hline & $\begin{array}{l}\text { LaMontagne } \\
\text { et al., } 2003\end{array}$ & $\begin{array}{l}\text { Charette } \\
\text { et al., } 2014\end{array}$ & $\begin{array}{l}\text { Nelson } \\
\text { et al., } 2016\end{array}$ & $\begin{array}{l}\text { Duparc- } \\
\text { Alegria } \\
\text { et al., } 2018\end{array}$ & $\begin{array}{l}\text { Tomaszek } \\
\text { et al., } 2019\end{array}$ & $\%$ \\
\hline $\begin{array}{l}\text { 1. Was true randomisation used for } \\
\text { assignment of participants to treatment } \\
\text { groups? }\end{array}$ & Y & Y & U & Y & Y & 80 \\
\hline $\begin{array}{l}\text { 2. Was allocation to treatment groups } \\
\text { concealed? }\end{array}$ & $Y$ & Y & U & Y & Y & 80 \\
\hline 3. Were treatment groups similar at baseline? & Y & Y & Y & Y & Y & 100 \\
\hline $\begin{array}{l}\text { 4. Were participants blind to treatment } \\
\text { assignment? }\end{array}$ & U & $N$ & $N$ & $N$ & Y & 20 \\
\hline $\begin{array}{l}\text { 5. Were those delivering treatment blind to } \\
\text { treatment assignment? }\end{array}$ & $\mathrm{N}$ & $N$ & $N$ & $N$ & $U$ & 0 \\
\hline $\begin{array}{l}\text { 6. Were outcome assessors blind to treatment } \\
\text { assignment? }\end{array}$ & N & $N$ & Y & Y & $U$ & 40 \\
\hline $\begin{array}{l}\text { 7. Were treatment groups treated identically } \\
\text { other than the intervention of interest? }\end{array}$ & $Y$ & Y & Y & Y & Y & 100 \\
\hline $\begin{array}{l}\text { 8. Was follow-up complete, and if not, were } \\
\text { strategies to address incomplete follow-up } \\
\text { utilised? }\end{array}$ & $\mathrm{N}$ & Y & $N$ & $\mathrm{~N}$ & $\mathrm{~N}$ & 20 \\
\hline $\begin{array}{l}\text { 9. Were participants analysed in the groups to } \\
\text { which they were randomised? }\end{array}$ & $Y$ & Y & Y & Y & Y & 100 \\
\hline $\begin{array}{l}\text { 10. Were outcomes measured in the same way } \\
\text { for treatment groups? }\end{array}$ & $Y$ & Y & Y & Y & Y & 100 \\
\hline 11. Were outcomes measured in a reliable way? & Y & Y & Y & Y & Y & 100 \\
\hline 12. Was appropriate statistical analysis used? & Y & Y & Y & Y & Y & 100 \\
\hline $\begin{array}{l}\text { 13. Was the trial design appropriate, and any } \\
\text { deviations from the standard RCT design } \\
\text { (individual randomisation, parallel groups) } \\
\text { accounted for in the conduct and analysis } \\
\text { of the trial? }\end{array}$ & Y & Y & Y & Y & Y & 100 \\
\hline Score & 9 & 10 & 8 & 10 & 10 & \\
\hline
\end{tabular}


Table 3: Characteristics of included studies

\begin{tabular}{|c|c|c|c|c|c|c|c|c|}
\hline Study details & $\begin{array}{l}\text { Study } \\
\text { design }\end{array}$ & $\begin{array}{l}\text { Participants } \\
\text { details } \\
\text { (EG/CG) }\end{array}$ & $\begin{array}{l}\text { Setting and } \\
\text { location }\end{array}$ & $\begin{array}{l}\text { Intervention } \\
\text { (frequency, } \\
\text { duration) }\end{array}$ & Comparator & $\begin{array}{l}\text { Outcome } \\
\text { measures }\end{array}$ & $\begin{array}{l}\text { Measurements } \\
\text { points }\end{array}$ & $\begin{array}{l}\text { Outcomes } \\
\text { (EG/CG) }\end{array}$ \\
\hline $\begin{array}{l}\text { LaMontagne et } \\
\text { al., 200340 } \\
\text { (USA) }\end{array}$ & $\begin{array}{l}\text { RCT } \\
\text { with four } \\
\text { groups }\end{array}$ & $\begin{array}{l}n=109 \\
\text { Information only } n=27 \\
\text { Coping only } n=27 \\
\text { Information plus coping } \\
n=30 \\
\text { Control group } n=25 \text {. } \\
\text { Ages: } 11 \text { to } 18 \text { years }\end{array}$ & $\begin{array}{l}\text { During } \\
\text { preoperative } \\
\text { orthopaedic } \\
\text { clinic visit }\end{array}$ & $\begin{array}{l}\text { Cognitive- } \\
\text { behavioural } \\
\text { Intervention } \\
\text { delivered by video } \\
\text { (one session, 8-10 } \\
\text { minutes) }\end{array}$ & Usual care & STAIC & $\begin{array}{l}\text { Preoperative (day } \\
\text { before surgery) } \\
\text { Post-operative (day } \\
\text { two after surgery) }\end{array}$ & $\begin{array}{l}\text { Information } \\
\text { only: } \\
38,93(7,10) \\
\text { Coping only: } \\
37,07(6,38) \\
\text { Control group: } \\
39,88(8,28)\end{array}$ \\
\hline $\begin{array}{l}\text { Charette et al., } \\
2014^{41} \\
\text { (Canada) }\end{array}$ & $\begin{array}{l}\text { RCT (pilot } \\
\text { study) }\end{array}$ & $\begin{array}{l}n=40(20 / 20) \\
\text { Ages: } 11 \text { to } 20 \text { years }\end{array}$ & $\begin{array}{l}\text { At hospital on } \\
\text { the day before } \\
\text { surgery }\end{array}$ & $\begin{array}{l}\text { A DVD providing } \\
\text { information and } \\
\text { demonstration of } \\
\text { guided imagery, } \\
\text { relaxation and } \\
\text { education (one } \\
\text { session, } 30 \text { minutes) }\end{array}$ & Usual care & STAI-Y & $\begin{array}{l}\text { Preoperative (day } \\
\text { before) Post-operative } \\
\text { (day of discharge) } \\
\text { and follow-up (one } \\
\text { month follow-up visit) }\end{array}$ & $\begin{array}{l}\text { EG: } 47,25 \\
(3,37) \\
\text { CG: } 47,85 \\
(5,93)\end{array}$ \\
\hline $\begin{array}{l}\text { Nelson et al., } \\
2016^{42} \\
\text { (USA) }\end{array}$ & RCT & $\begin{array}{l}n=41(19 / 22) \\
\text { Ages: } 10 \text { to } 19 \text { years }\end{array}$ & $\begin{array}{l}\text { During } \\
\text { preoperative } \\
\text { visit }\end{array}$ & $\begin{array}{l}\text { Relaxation training } \\
\text { program video (one } \\
\text { session, 20-30 } \\
\text { minutes) }\end{array}$ & Usual care & NRS & $\begin{array}{l}\text { Preoperative } \\
\text { and post-operative } \\
\text { (day two after } \\
\text { surgery) }\end{array}$ & $\begin{array}{l}\text { EG: } 3,5(2,7) \\
\text { CG: } 3,7(2,9)\end{array}$ \\
\hline $\begin{array}{l}\text { Duparc-Alegria et } \\
\text { al., } 2018^{43} \\
\text { (France) }\end{array}$ & RCT & $\begin{array}{l}n=118(59 / 59) \\
\text { Ages: } 10 \text { to } 18 \text { years. } \\
\text { [EG: } 14,8(13-15,9) \\
\text { CG: } 14,6(13,5-15,7)]\end{array}$ & $\begin{array}{l}\text { In the } \\
\text { operating room } \\
\text { just before } \\
\text { anaesthesia }\end{array}$ & $\begin{array}{l}\text { Short session of } \\
\text { hypnosis (one } \\
\text { session, 5-10 } \\
\text { minutes) }\end{array}$ & Usual care & VAS-A & $\begin{array}{l}\text { Preoperative (day } \\
\text { before surgery) } \\
\text { Post-operative (day } \\
\text { one after surgery) }\end{array}$ & $\begin{array}{l}\text { EG: } 1[\min 0 ; \\
\max 8] \\
\text { CG: } 0[\min 0 ; \\
\max 7]\end{array}$ \\
\hline $\begin{array}{l}\text { Tomaszek et al., } \\
2019^{44} \\
\text { (Poland) }\end{array}$ & RCT & $\begin{array}{l}n=112(56 / 56) \\
\text { Ages: } 9 \text { to } 18 \text { years. } \\
\text { [EG: } 14,3(2,2) \\
\text { CG: } 14,2(2,2)]\end{array}$ & $\begin{array}{l}\text { Day before } \\
\text { surgery }\end{array}$ & $\begin{array}{l}\text { Additional } \\
\text { information support } \\
\text { from a psychologist } \\
\text { (one session, } 45 \\
\text { minutes) }\end{array}$ & Usual care & $\begin{array}{l}\text { STAIC and STAIY } \\
\text { Expressed as sten } \\
\text { scores from 1-10; } \\
\text { sten score of } 5 \text { or } \\
6 \text {-moderate level } \\
\text { of anxiety; } 7 \text { and } \\
\text { more - high level } \\
\text { of anxiety }\end{array}$ & $\begin{array}{l}\text { Preoperative (day } \\
\text { before surgery) and } \\
\text { post-operative (48 } \\
\text { hours after surgery) }\end{array}$ & $\begin{array}{l}\text { EG: 5,5 (4-7) } \\
\text { CG: 5,5 (5-7) }\end{array}$ \\
\hline
\end{tabular}

$E G=$ Experimental group, $C G=$ Control group, NRS = Numeric Rating Scale, RCT = Randomised Control Trial, STAIC = State-Trait Anxiety Inventory for Children, STAI-Y = State-Trait Anxiety Inventory form Y, USA = United States of America, VAS-A = Visual Analogue Scale - Anxiety

review authors decided to keep the study for inclusion in this review.

There were no substantial differences in age, sex, ethnic background or socioeconomic status among the study groups. Surgery for scoliosis s0-43 $^{-4}$ and thoracic surgery ${ }^{44}$ were the most common. Patients with mental disorders, cognitive deficits ${ }^{40,41,43,44}$, chronic illness or problems with verbal communication were not eligible ${ }^{44}$.

\section{Characteristics of the intervention}

All the interventions were delivered during the preoperative period and involved different methods such as, cognitive-behavioural techniques using information and coping strategies ${ }^{40}$, hypnosis ${ }^{43}$, guided imagery and education ${ }^{41}$, and training and relaxation ${ }^{42}$. One study used 'additional information' delivered by a psychologist ${ }^{44}$. In addition to the main intervention, four studies included an education/information component ${ }^{40-42,44}$. In one study, the intervention was delivered by the music therapists ${ }^{42}$, in two studies the interventions were facilitated by nurses ${ }^{41,43}$.

\section{Outcome measures}

Regarding the outcome and assessment tools, anxiety was measured using self-administered instruments $40,41,44$ or instruments filled out by the researcher ${ }^{42,43}$. The most commonly used instrument was STAI-C ${ }^{40,44}$ or STAl ${ }^{41,44}$. One study used the VAS-A $\mathrm{A}^{43}$ and another used the $\mathrm{NRS}^{42}$. With regard to timing of the assessment, the studies assessed anxiety before delivering the intervention in the preoperative period, and in the post-operative 
period, either the day after surgery ${ }^{43}$ or on day two ${ }^{40,42,44}$. In one study the post-intervention evaluation was done on the day of discharge ${ }^{41}$. Only the study by Charette et al. ${ }^{41}$ assessed anxiety at three stages: preintervention, the day of discharge and in the follow-up consultation, one-month after surgery.

\section{Effectiveness of non- pharmacological interventions}

In the Charette et al. study, the follow-up comparison between the experimental group and the control group $(44,75+-3,46$ vs 47,68 +- 4,42) showed that the former tended to have lower anxiety levels ( $p=0.03)$, with moderate effect size. However, the evaluations made on the day of the surgery and the discharge day were not statistically significant ${ }^{41}$.

In the Nelson et al. study, the use of relaxation training had significant effects on anxiety reduction in both groups. Despite the treatment group presenting a slightly greater anxiety reduction there were no statistically significant differences between the two groups ${ }^{42}$.

In the Duparc-Alegria study, when using a short session of hypnosis there were no differences between groups but a significant decrease in anxiety levels was shown in both groups $(p<0.0001)^{43}$.

In the Tomaszek et al. study that delivered additional information, the patients in the experimental group showed significantly lower levels of state anxiety at 48 hours after surgery than prior to the procedure $(Z=3.357, p<0.001)^{44}$. Conversely, when comparing anxiety levels in the preoperative and post-operative periods, they were significantly increased in the control group $(Z=2.146, p=0.031)^{44}$. Regardless of the group, participant's correlation established statistically significant associations between preoperative and post-operative state anxiety $(\mathrm{R}=0.6, \mathrm{t}=8.26, \mathrm{p}<0.001)$, preoperative state anxiety and trait anxiety $(R=0.4, t=4.92, p<0.001)$, postoperative state anxiety and trait anxiety $(R=0.5, t=6.96, p<0.001)$ and perioperative state anxiety and patient age $(R=-0.4, p<0.001)^{44}$.

LaMontagne et al. analysed cognitivebehavioural interventions for reducing adolescent's perioperative anxiety using information alone, coping strategies alone, and a combination of both information and coping strategies ${ }^{40}$. The ANOVA analysis showed no difference between the groups ( $F$ [3.11] .92, $p=0.44$ ). When analysing results for the "combined information and coping' group, the results were shown to be more than twice the size of the other groups (63.50) and with a negative slope (-0.78) indicating that lower levels of post-operative anxiety were associated with higher levels of preoperative anxiety ${ }^{40}$. In the same study, for the younger adolescents ( $<13.25$ years), the interventions that included coping strategies were shown to be more effective in the reduction of anxiety in the post-operative period than the interventions that did not include coping strategies ${ }^{40}$.

\section{Meta-analysis}

The meta-analysis was conducted including three studies ${ }^{40-42}$ which corresponded to a sample of 136 adolescents in the perioperative period. As listed in Figure 2, the findings suggest no differences in anxiety when NPIs are applied compared to standard care (SMD -0.14, 95\% Cl -0.48 to 0.20, $p=0.42$ ).

\section{Discussion}

To our knowledge, this is the first systematic review presenting an overview of the effect of NPIs with exclusive focus on the adolescent population in the perioperative period. The identified studies used NPIs such as cognitive-behavioural techniques using 'information' and coping strategies, hypnosis,

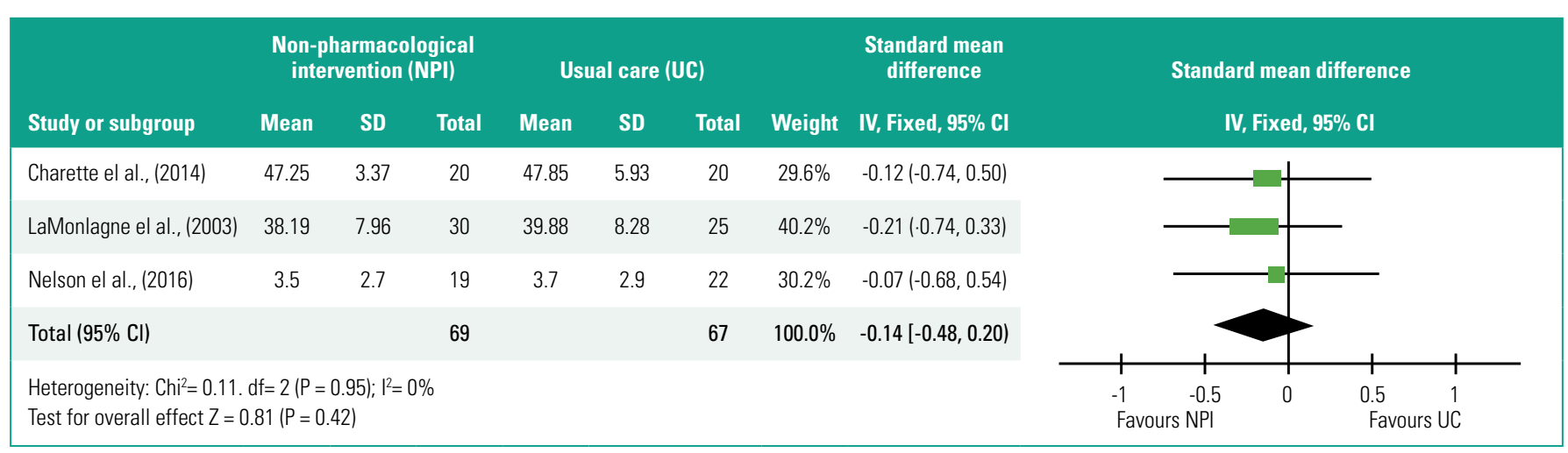

Figure 2: Forest plot of non-pharmacological interventions (NPIs) compared with the usual care (UC) for anxiety in adolescents in the perioperative period 
guided imagery, relaxation training and information ${ }^{40-44}$. Although the NPIs could be implemented by any professional, nurses were the professionals who were most often involved in the conception, implementation and evaluation of these interventions ${ }^{36}$. Additionally, the duration of interventions included in this review was diverse. The optimal frequency, 'dosage' and timing for the delivery of NPIs to manage adolescent anxiety in the perioperative period needs improvement as it is recommended in similar applications of NPIs ${ }^{32,36}$. The majority of these NPIs do not require extra time or additional costs for their implementation; however, it is important to evaluate their feasibility in order to develop protocols and establish multidisciplinary routines in perioperative teams ${ }^{45}$.

The low number of studies presenting specific results for the adolescent population and the variability of interventions made it impossible to analyse the effect of each intervention independently. However, the review authors overcame this limitation by grouping the interventions to perform the metaanalysis and analyse their overall effect.

Mixed findings about the value of 'additional' information suggest that the adolescent population should previously be carefully evaluated for developmental characteristics and the trait and state of their anxiety ${ }^{40,44}$. LaMontagne et al. found that in adolescents with high trait anxiety, the intervention was revealed to be more effective when used with information. However, when anxiety was evaluated as low in the preoperative period, the use of a single intervention was more effective in reducing anxiety following surgery than a combination of interventions. A combined approach, that offers more information and advice than the adolescents can assimilate, can make them more anxious ${ }^{40}$. Conversely, Tomaszek et al. concluded that despite the delivery of additional information by a psychologist, adolescents with high levels of trait anxiety did not benefit from it. Only adolescents with lower levels of trait anxiety benefited from the information support prior to the surgical procedure ${ }^{44}$. These results could be related to the 'dose' or amount of information delivered. Beyond the intervention, the information 'dose' should be tailored to the needs of the individual and fit their developmental characteristics, preserving a low state of anxiety during the perioperative period ${ }^{32,40}$. Similarly, a qualitative study found that lack of information and understanding about the procedure were the main reasons for adolescents to become apprehensive ${ }^{46}$. Moreover, an integrative review identified that adolescents want to be involved in their perioperative care, revealing the need for information prior to the surgical procedure which will subsequently have a positive effect on their pain management and post-operative recovery, both in the hospital and at home ${ }^{17}$.

The study using guided imagery showed no short-term effect on the adolescents' anxiety level. But in the follow-up evaluation, one month after the surgery, the adolescents' anxiety levels tended to be lower. Guided imagery is effective in the preoperative period and is not known to be associated with adverse effects thus being a safe option to improve recovery ${ }^{32,47}$. A meta-analysis of the effectiveness of guided imagery preoperatively has shown it to be effective in relieving preoperative state anxiety in children $(d=-3.71)$ and preoperative trait anxiety in adults $(d=-0.64)^{47}$.

Despite no statistical significance, the use of relaxation and training showed a slight reduction in adolescent anxiety levels ${ }^{42}$. The use of relaxation and guided imagery techniques with children was shown to be effective in anxiety reduction in the perioperative period ${ }^{45}$. A systematic review with meta-analysis of the effects of relaxation therapy on adults with anxiety disorder showed this technique is effective ${ }^{48}$.

With the hypnosis intervention, there were no differences and a significant decrease in anxiety levels was seen in both groups ${ }^{43}$. A possible explanation for this result is the fact that the anaesthetic nurses were trained with hypnotic techniques for the purposes of the study and that impacted the way the trained person cared for both the intervention and control group. This training induces changes in language, such as the use of positive suggestions ${ }^{43}$ and the use of these desirable and reassuring words can improve patient perception and subjective experience ${ }^{49}$. Additionally, hypnosis in adolescents uses natural hypnotic abilities that teens bring to the clinical encounter. Adolescents are also highly responsive to hypnotic therapeutic suggestions when compared to adult patients ${ }^{50}$.

The results of the current review show that the effect of using NPIs to reduce adolescent anxiety in the perioperative period is not statistically significant. The evidence gathered is not strong enough to make effective recommendations in favour of or against the use of NPIs with adolescents in the perioperative period. However, individually each study showed beneficial effects from the application of each intervention and highlighted some concerns to be accounted for when delivering NPIs to adolescents, such as age, maturity, previous trait and state of anxiety, and the characteristics of the intervention. 


\section{Strengths and limitations}

This review filled an existing gap in the literature by assessing the effectiveness of NPIs in managing anxiety in adolescents during the perioperative period. However, this review has some limitations. Only five studies met the inclusion criteria, and these had small sample sizes of less than 60 participants in each study group. The type of surgical procedure and anxiety measurement instrument also differed among the studies. Although it was not possible to draw conclusions, it was highlighted that it is of utmost importance to consider their age, when evaluating the effect of the interventions on the adolescent population, and separate early adolescents from late adolescents.

Another limitation was the absence of the long-term effect (follow-up) evaluation in four of the five studies. Furthermore, there is language bias as only English, Spanish or Portuguese language studies were considered for inclusion.

\section{Conclusion}

This review examined the best available evidence on the effectiveness of NPIs in managing anxiety in adolescents during the perioperative period. Although anxiety represents a common problem in the perioperative period, limited studies were found regarding the effect of NPIs implemented and evaluated exclusively in the adolescent population. The topic of information/education was present in four studies revealing it as an important resource, especially when delivered alongside the NPIs at their implementation stage. Nevertheless, this review also showed that the trait and state of adolescent anxiety should be evaluated before intervention and information delivery. Although the studies do not report a statistically significant difference in anxiety, a slight improvement in score was found after NPI delivery compared to before NPI delivery and this was considered clinically relevant.

The recommendations from this review can be used as a tool to guide the design of future studies, refining, exploring and utilising non-pharmacological interventions to their full potential, with the aim of successful management of anxiety in adolescents during the perioperative period.

\section{References}

1. Fortier MA, Martin SR, Chorney JM, Mayes LM, Kain ZN. Preoperative anxiety in adolescents undergoing surgery: A pilot study. Pediatr Anesth 2011;21(0):969-973.

2. Monahan JC. Using an age-specific nursing model to tailor care to the adolescent surgical patient. AORN J 2014;99(6):733-749.

3. Goldschmidt K, Woolley A. Using technology to reduce childrens' anxiety throughout the perioperative period. J Pediatr Nurs 2017;36:256-258.

4. Instituto Nacional de Estatistica [Satistics Portugal]. Estatística da Saúde 2018 [Health Statistics 2018] [Internet]. Lisbon: Instituto Nacional de Estatistica [Satistics Portugal]; 2020 [cited ]. Available from: www. ine.pt/ngt_server/attachfileu.jsp?look_ parentBoui=427101926\&att_display=n\&att_ download $=y$.

5. World Health Organization (WHO). Adolescent health [Internet]. Geneva: WHO; 2020 [cited ]. Available from: www. who.int/health-topics/adolescenthealth/\#tab=tab_1.

6. Barrett DE. The three stages of adolescence. The High School Journal 1996;79(4):333-339.

7. Sawyer S, Azzopardi P, Wickremarathne D, Patton G. The age of adolescence. Lancet Child Adolesc Health 2018;00(0):1-6.

8. Holzman RS. Perioperative care of adolescents. Curr Opin Anesthesiol 2013;26(3):333-339.

9. Aytekin A, Doru Ö, Kucukoglu S. The effects of distraction on preoperative anxiety level in children. J Perianesth Nurs 2016;31(1):56-62.
10. Chieng Y, Chan W, Klainin-Yobas P, He H. Perioperative anxiety and postoperative pain in children and adolescents undergoing elective surgical procedures: A quantitative systematic review. J Adv Nurs 2014;2(70):243-255.

11. Rantala A, Pikkarainen M, Miettunen J, He HG, Pölkki T. The effectiveness of web-based mobile health interventions in paediatric outpatient surgery: A systematic review and meta-analysis of randomized controlled trials. J Adv Nurs preprint.

12. Chow CH, Van Lieshout RJ, Schmidt LA, Dobson KG, Buckley N. Systematic review: Audiovisual interventions for reducing preoperative anxiety in children undergoing elective surgery. J Pediatr Psychol 2016;41(2):182-203.

13. Manyande A, Cyna AM, Yip P, Chooi C, Middleton P. Non-pharmacological interventions for assisting the induction of anaesthesia in children. Cochrane Database Syst Rev 2015(7):Cd006447.

14. Lee KC, Chao YH, Yiin JJ, Chiang PY, Chao YF. Effectiveness of different music-playing devices for reducing preoperative anxiety: A clinical control study. Int J Nurs Stud 2011;48(10):1180-1187.

15. Brewer S, Gleditsch SL, Syblik D, Tietjens ME, Vacik HW. Pediatric anxiety: Child life intervention in day surgery. J Pediatr Nurs 2006;21(1):13-22.

16. Rullander AC, Isberg $S$, Karling M, Jonsson $H$, Lindh V. Adolescents' experience with scoliosis surgery: A qualitative study. Pain Manag Nurs 2013;14(1):50-59.

17. Pestana-Santos M, Reis Santos M, PestanaSantos A, Pinto C, Lomba L. Perioperative anxiety in adolescents - manifestations and control needs: An integrative review. Revista ROL de Enfermería. 2020;43(1):312-321.

18. Spielberger CD. State?Trait Anxiety Inventory. In: Weiner IB, Craighead WE, editors. The Corsini Encyclopedia of Psychology. 1: New Jersey: John Wiley and Sons, Inc.; 2010.

19. Association AP. Diagnostic and Statistical Manual of Mental Disorders, DSM-5, Portuguese edition. $5^{\text {th }}$ ed. Lisbon: Climepsi Editores; 2014, p. 1121.

20. Pop-Jordanova N. Different clinical expression of anxiety disorders in children and adolescents: Assessment and treatment. Prilozi 2019;40(1):5-40.

21. Bailey L. Strategies for decreasing patient anxiety in the perioperative setting. AORN J 2010;92(4):445-460.

22. Caumo W, Broenstrub J, Fialho L, Petry S, Brathwait O, Bandeira D et al. Risk factors for postoperative anxiety in children. Acta Anaesthesiol Scand 2000;44(7):782-789. 
23. Casey B. Beyond simple models of selfcontrol to circuit-based accounts of adolescent behavior. Annu Rev Psychol 2015;66:295-319.

24. Fronk E, Billick SB. Pre-operative anxiety in pediatric surgery patients: Multiple case study analysis with literature review. Psychiat Q 2020;91:1439-1451.

25. Kain ZN, Mayes LC, O'Connor TZ, Cicchetti DV. Preoperative anxiety in children: Predictors and outcomes. Archi Pediat Adolesc Med 1996;150(12):1238-1245.

26. Kain ZN, Mayes LC, Caldwell-Andrews AA, Karas DE, McClain BC. Preoperative anxiety, post-operative pain, and behavioral recovery in young children undergoing surgery. Pediatrics 2006;118(2):651-658.

27. Li WH, Chung JOK, Ho KY, Kwok BMC. Play interventions to reduce anxiety and negative emotions in hospitalized children. BMC pediatrics 2016;16(1):1-9.

28. Fortier MA, Kain ZN. Treating perioperative anxiety and pain in children: A tailored and innovative approach. Pediatr Anesth 2015;25(1):27-35.

29. Cox RG, Nemish U, Ewen A, Crowe M-J. Evidence-based clinical update: Does premedication with oral midazolam lead to improved behavioural outcomes in children? Can J Anesth 2006;53(12):1213-1219.

30. Ordem dos Enfermeiros [Order of Nurses]. Guias Orientadores de Boa Prática em Enfermagem de Saúde Infantil e Pediátrica [Guide to Good Practice in Infant and Pediatric Health Patients]. Lisbon: Ordem dos Enfermeiros; 2011.

31. Ninot G. Non-pharmacological Interventions. New York: Springer; 2020.

32. Tick H, Nielsen A, Pelletier KR, Bonakdar R, Simmons S, Glick R et al. Evidencebased nonpharmacologic strategies for comprehensive pain care: The consortium pain task force white paper. Explore (NY) 2018;14(3):177-211.

33. Könsgen N, Polus S, Rombey T, Pieper D. Clowning in children undergoing potentially anxiety-provoking procedures: A systematic review and meta-analysis. Syst Rev 2019;8(1):1-12.
34. Chow CH, Rizwan A, Xu R, Poulin L, Bhardwaj $V$, Van Lieshout RJ et al. Association of temperament with preoperative anxiety in pediatric patients undergoing surgery: $A$ systematic review and meta-analysis. JAMA network open 2019;2(6):e195614-e.

35. Eijlers R, Utens E, Staals LM, de Nijs PFA, Berghmans JM, Wijnen RMH et al. Systematic review and meta-analysis of virtual reality in pediatrics: Effects on pain and anxiety. Anesth Analg 2019;129(5):1344-1353.

36. Pestana-Santos M, Pires R, Goncalves A, Parola V, Santos MR, Lomba L. Nonpharmacological interventions used in the perioperative period to prevent anxiety in adolescents: A scoping review. JBI Evidence Synthesis 2021; preprint.

37. Tufanaru C, Munn Z, Aromataris E, Campbell J, Hopp L. Chapter 3: Systematic reviews of effectiveness. In: Aromataris E, Munn Z, editors. Manual for Evidence Synthesis: Adelaide: JBI; 2020

38. Pestana-Santos M, Pereira MJ, Santos E, Lomba L, Santos MR. Effectiveness of nonpharmacological interventions to manage anxiety in adolescents in the perioperative period: A systematic review protocol. JBI Evidence Synthesis. 2021.

39. Tufanaru C, Munn Z, Stephenson M, Aromataris E. Fixed or random effects metaanalysis? Common methodological issues in systematic reviews of effectiveness. Int J Evid-based healthc 2015;13(3):196-207.

40. LaMontagne LL, Hepworth JT, Cohen F, Salisbury MH. Cognitive-behavioral intervention effects on adolescents' anxiety and pain following spinal fusion surgery. Nurs Res 2003;52(3):183-190.

41. Charette S, Fiola JL, Charest M-C, Villeneuve E, Théroux J, Joncas J et al. Guided imagery for adolescent post-spinal fusion pain management: A pilot study. Pain Manag Nurs 2015;16(3):211-220.

42. Nelson K, Adamek M, Kleiber C. relaxation training and postoperative music therapy for adolescents undergoing spinal fusion surgery. Pain Manag Nurs 2017;18(1):16-23.
43. Duparc-Alegria N, Tiberghien K, Abdoul $\mathrm{H}$, Dahmani S, Alberti C, Thiollier AF. Assessment of a short hypnosis in a paediatric operating room in reducing postoperative pain and anxiety: A randomised study. J Clin Nurs 2018;27(12):86-91.

44. Tomaszek L, Cepuch G, Fenikowski D. Influence of preoperative information support on anxiety, pain and satisfaction with post-operative analgesia in children and adolescents after thoracic surgery: $A$ randomised double blind study. Biomed Pap Med Fac Univ Palacky Olomouc Czech Repub 2019;163(2):172-178.

45. Vagnoli L, Bettini A, Amore E, De Masi $S$, Messeri A. Relaxation-guided imagery reduces perioperative anxiety and pain in children: A randomized study. Eur J Pediatr 2019;178(6):913-921.

46. Lööf G, Andersson? Papadogiannakis $\mathrm{N}$, Silén C. Children's own perspectives demonstrate the need to improve paediatric perioperative care. Nursing open 2019;6(4):1363-1371.

47. Álvarez-García C, Yaban Z. The effects of preoperative guided imagery interventions on preoperative anxiety and post-operative pain: A meta-analysis. Complement Ther Clin Pract 2020;38:101077.

48. Kim H-S, Kim EJ. Effects of relaxation therapy on anxiety disorders: A systematic review and meta-analysis. Arch Psychiatr Nurs 2018;32(2):278-284.

49. Fusco N, Bernard F, Roelants F, Watremez C, Musellec $\mathrm{H}$, Laviolle B et al. Hypnosis and communication reduce pain and anxiety in peripheral intravenous cannulation: Effect of language and confusion on pain during peripheral intravenous catheterization (KTHYPE), a multicentre randomised trial. $\mathrm{Br}$ J Anaesth 2020;124(3):292-298.

50. Sawni A, Breuner CC. Clinical hypnosis, an effective mind-body modality for adolescents with behavioral and physical complaints. Children 2017;4(4):19. 